\title{
Insight Into the Perioperative Management of Type 2 Diabetes
}

\author{
Syed Owais Zaidi ${ }^{1,2}$, Yusra Khan ${ }^{3}$, Bibi S. Razak ${ }^{1}$, Bilal Haider Malik ${ }^{1}$ \\ 1. Internal Medicine, California Institute of Behavioral Neurosciences and Psychology, Fairfield, USA 2. Internal \\ Medicine, Mukhtar Sheikh Hospital, Multan, PAK 3. Pharmacy, California Institute of Behavioral Neurosciences and \\ Psychology, Fairfield, USA
}

Corresponding author: Syed Owais Zaidi, owaiszaidi87@hotmail.com

\begin{abstract}
Diabetic people are at risk of developing acute complications when exposed to stress. Surgery brings a stressful period when the patient is exposed not only to surgical stress but also the effects of medications used during that particular period. The patient's comorbidities can influence the perioperative management of diabetes. Poorly controlled diabetes can complicate the hospital course.
\end{abstract}

The literature was searched through PubMed and the articles of the last 5 years, from 2014 to 2019, were looked into. The studies available as a free text, in the English language and related to humans, were included. Inclusion criteria also included adults with type 2 diabetes undergoing surgery.

The perioperative management of diabetes is a challenging one. Apart from the diabetes control; comorbidities, general health, intake, and interaction of medications both anti-diabetic and non-diabetic, type and duration of surgery, are some of the factors that influence the outcome of the surgery. With a variety of options available to manage diabetes currently, it is important to have a good insight into their effects to prevent complications to occur and ensure safe discharge from the hospital. The good control of diabetes is essential in bringing favorable outcomes.

The perioperative management of diabetes should be individualized. Oral anti-hyperglycemic medications, other than sulfonylureas and SGLT2 inhibitors, provide a reasonable alternative to insulin and can be continued safely perioperatively depending upon the type of surgery and the patient is expected to resume oral intake soon postoperatively.

Received 11/27/2019

Review began 01/28/2020 Review ended 02/02/2020 Published 02/04/2020

() Copyright 2020 Zaidi et al. This is an open access article distributed under the terms of the Creative Commons Attribution License CC-BY 4.0., which permits unrestricted use, distribution, and reproduction in any medium, provided the original author and source are credited.
Categories: Anesthesiology, Endocrinology/Diabetes/Metabolism, Internal Medicine Keywords: hyperglycemia, perioperative management, diabetes, high blood sugars

\section{Introduction And Background}

The diabetic population is prone to have a complicated hospital course along with the risk of perioperative complications [1]. According to the figure quoted by International Diabetes Federation in 2017, 425 million people between the age range of 18-99, are affected with diabetes and this number is expected to touch 693 million in 2045 [2]. It is essential to review the treatment of diabetes and its complications before undertaking surgery with regard to its effects on fluid and electrolyte balance and cardiovascular system, in terms of interactions with other drugs and the other illnesses like kidney disease, autonomic disorders, coronary artery disease, vascular disease, and high blood pressure [1].

Screening for diabetes is recommended in every patient being planned for surgery [1]. A review of a recent hemoglobin A1c (HbA1c) level before surgery permits risk assessment and attempt to achieve good glycemic control (HbA1c < $69 \mathrm{mmol} / \mathrm{l}$ ) [3-4]. Hemoglobin A1c (HbA1c) provides an average estimate of blood sugars over the last three months in diabetic patients, thereby not only representing the quality of diabetic control but also permits review and adjustment in treatment to achieve the target, in addition to that, its raised value in some studies indicates a likelihood of early postoperative infection and myocardial infarction [5-6].

It has been found in the meta-analysis of studies involving patients with diabetes undergoing surgical procedures only that the blood sugar control in the range of $150-200 \mathrm{mg} / \mathrm{dl}(8.3-11.1 \mathrm{mmol} / \mathrm{l})$ is associated with decreased perioperative mortality and stroke than a more relaxed target of $>200 \mathrm{mg} / \mathrm{dl}$ (11.1 $\mathrm{mmol} / \mathrm{l})$. Moreover, strict control between 100 and $150 \mathrm{mg} / \mathrm{dl}$ (5.6-8.3 mmol/l) does not result in an added advantage [7]. Surgery in diabetics places them at high risk to develop postoperative infections due to the adverse effects of diabetes on their immune status, wound healing, and blood supply through small vessels [8-10].

Perioperative treatment to achieve good control of diabetes with insulin, either in the form of infusion or bolus has been used over the years due to its rapid action and easy adjustment, however, due to the variability in insulin resistance among the patients, the response is unpredictable and optimal regimen is yet 


\section{Cureus}

to be known $[4,11-15]$. The advent of new treatments in diabetes opens the door of discussion regarding achieving control of diabetes, timing to withhold medications, an adjustment in doses or modification in the treatment, and interactions of the drugs perioperatively. The literature is reviewed to find the answer to these questions.

The search of the literature review is done using the internet and PubMed using the following six regular keywords and three MeSH Words:

\section{Regular keywords}

1. Perioperative: It brings the results of 116379.

2. Diabetes: It shows 709582 results.

3. Management: It comes up with the 2830280 results.

4. Complications: It reveals 3190876 results.

5. Insulin: It produces 400938 results.

6. Antidiabetics: It presents with 260645

Regular keywords are summarized in Table 1 .

\begin{tabular}{|c|c|c|}
\hline KEYWORDS & DATABASE & NUMBER OF RESULTS \\
\hline Perioperative & PubMed & 116379 \\
\hline Diabetes & PubMed & 709582 \\
\hline Management & PubMed & 2830280 \\
\hline Complications & PubMed & 3190876 \\
\hline Insulin & PubMed & 400938 \\
\hline Antidiabetics & PubMed & 260645 \\
\hline
\end{tabular}

\section{TABLE 1: Regular keywords}

\section{MeSH strategy}

The below-mentioned picture emerges by employing MeSH strategy.

1. Perioperative is searched through MeSH and produces six results.

2. Diabetes in MeSH reveals 100 results.

3. Management via MeSH produces 53 results.

MeSH strategy is described in Table 2.

\section{MeSH WORDS}

Perioperative

Diabetes

Management

\section{NUMBER OF RESULTS}

6

100

53

TABLE 2: MeSH strategy 


\section{Inclusion criteria}

The following inclusion criteria were used while searching the literature:

1. The last five years of articles were searched from 2014 to 2019.

2. Only free text available was made part of the search.

3. The studies related to humans only were taken into consideration.

4. Adults with type 2 diabetes were included in the review.

5. The review articles and randomized control trials (RCTs) were made part of the review.

6. All the articles were peer reviewed.

\section{Ethical issue}

All the data were collected ethically and legally.

\section{Quality assessment tool}

No quality assessment tool was applied.

\section{Review}

\section{Perioperative management of diabetes}

The common exercise is to hold all oral anti-diabetic medications on the day of undertaking surgery; however, this strategy does not deem fit for those patients undergoing surgery for a shorter period or are expected to resume their diet quickly or are discharged after having a short stay [16-17].

Those patients in whom the diet is withheld for a shorter period, the Association of Anesthetists of Great Britain and Ireland (AAGBI) guideline recommends an individualized approach with the option of carrying on with the antihyperglycemic medications that do not cause low blood sugars and metformin is no exception [18].

A joint Anesthesiology and Diabetology position statement from France also reinforces the idea of sticking with the non-insulin medications in daycare surgeries and only to be stopped in major procedures [19].

Given that, the existence of no definitive strategy to manage blood sugars perioperatively and diverse recommendations from different clinical bodies, it is not unexpected to observe in the audits like National Confidential Enquiry into Patient Outcome and Death (NCEPOD) study, the different approaches being employed in clinical settings to achieve blood glucose targets [20].

\section{Anti-hyperglycemic medications}

Metformin

It is the recommended first-line drug to be used in treating type 2 diabetes unless contraindicated [1]. In the past, it is stopped for about 48 hours before surgery because of the overestimated fear of lactic acidosis [2122]. However, it is prudent to assess the following risk factors before deciding it to continue preoperatively or restart postoperatively [5]:

i. Renal impairment

ii. Use of contrast agents

iii. Dehydration

iv. Severe heart failure $(\mathrm{EF}<30 \%)$

Recently, the US Food and Drug Authority (FDA) has permitted it to continue unless the estimated glomerular filtration rate (eGFR) falls below $30 \mathrm{ml} / \mathrm{min} / 1.73 \mathrm{~m} 2[1]$.

The American Diabetes Association (ADA) proposes holding of metformin on the day of surgery whereas the Association of Anesthetists of Great Britain and Ireland (AAGBI) suggests to continue it with the rest of the oral anti-diabetic medications other than sulfonylureas and sodium-glucose transport inhibitors (SGLTIs) on 
the day of procedure as it does not cause low blood sugars [16, 23]. It might be safe to restart 48 hours after the major procedure and making sure of the adequate functioning of the kidney [5].

\section{Sulfonylureas}

Sulfonylureas have been in the horizon of treatment of diabetes for about 70 years and a usual strategy to withhold it on the day of surgery remains plausible as it is associated with a higher risk of asymptomatic hypoglycemia compare to other antihyperglycemic medications demonstrated in a Continuous Glucose Monitoring (CGM) study [1, 24].

A review of meta-analysis showed that high risk is attached with the use of sulfonylureas in causing hospitalization, congestive cardiac failure, and mortality [25].

Sodium-Glucose Co-Transporters 2 (SGLT2) Inhibitors

It is a relatively new class of drugs added to the armamentarium of diabetes management that is associated with good blood glucose control, decreased plasma volume, renal protection, and weight loss [26-28]. It works by facilitating the passage of blood glucose and sodium in the urine irrespective of insulin [29]. However, it is linked with genitourinary infections and diabetic ketoacidosis (DKA) especially euglycemic DKA [1, 30-31]. The occurrence of euglycemic DKA is likely to increase in the peri - and postoperative period if they are not stopped perioperatively or restarted very soon postoperatively [32-35]. The awareness of a risk of developing euglycemic is very important to those who undergo surgery and a very high index of suspicion should be present not to miss it [1]. SGLT2 inhibitors should be restarted postoperatively when the patient looks clinically well and resumes and tolerates his oral intake properly [1].

At present, there is no agreement on the withholding of SGLT2 inhibitors before surgery but the general strategy is to stop them before 24-72 hours or even longer [1, 34-35].

Dipeptidyl Peptidase 4 (DPP 4) Inhibitors

Their use is associated with low risk of hypoglycemia and to stick or discontinue with it perioperatively is unlikely to produce any significant complications and either strategy is acceptable [1].

Glucagon-Like Peptide 1 (GLP-1) Agonists

They are administered through injections and are not linked to produce hypoglycemia instead of nausea and vomiting can occur. Their long - term use is associated with cardiovascular benefit [1, 16, 36-41].

The glucose control is better achieved through GLP - 1 agonist in comparison to insulin as shown in two randomized control studies of cardiac and non-cardiac patients undergoing surgery [16, 42]. However, gastrointestinal adverse effects may become limiting factors to their use [1]. Therefore, either plan of going with or against it perioperatively is workable [1].

Insulin

Perioperative insulin-based management in the form of basal-bolus is quite effective in attaining blood glucose targets than intermittent bolus with rapid-acting insulin in type 2 diabetes [43]. Insulin infusion is also an option and can be used in critical and non-critical situations [1].

Degludec has a long half-life of more than 42 hours and current data are not enough to determine its effect on perioperative blood sugars $[1,5]$.

The summary of antidiabetic medications used perioperatively is outlined in Table 3. 


\section{Cureus}

Summary of Perioperative Use of Anti-Diabetic Medications

Metformin

The American Diabetes Association (ADA) proposes holding of metformin on the day of surgery whereas the Association of Anesthetists of Great Britain and Ireland (AAGBI) suggests to continue it with the rest of the oral anti-diabetic medications other than sulfonylureas and sodiumglucose transport inhibitors on the day of the procedure as it does not cause low blood sugars. It might be safe to restart 48 hours after the major procedure and making sure of the adequate functioning of the kidney

Sulfonylurea

The usual strategy to withhold it on the day of surgery remains plausible

Dipeptidyl peptidase 4 (DPP4) inhibitors

To continue or discontinue it perioperatively is unlikely to produce any significant complications and either strategy is acceptable

Sodium-glucose co-transporters 2 (SGLT2) inhibitors

At present, there is no agreement on the withholding of SGLT2 inhibitors before surgery but the general strategy is to stop them before 24-72 hours or even longer

Glucagon-like peptide 1 (GLP1) agonists

Gastrointestinal adverse effects may become limiting factors to their use. Therefore, either plan of going with or against it perioperatively is workable

Insulin

Perioperative insulin - based management in the form of basal-bolus is quite effective in attaining blood glucose target than intermittent bolus with rapid-acting insulin in type 2 diabetes. Insulin infusion is also an option and can be used in critical and non-critical situations. Degludec has a long half-life of more than 42 hours and current data are not enough to determine its effect on perioperative blood sugars

TABLE 3: Summary of perioperative use of anti-diabetic medications

\section{Assessment of control of blood glucose levels}

Perioperative assessment of diabetic control is paramount and is evaluated by the following two methods $[5]$ :

i. Hemoglobin A1c (HbA1c)

ii. Blood sugar level

There are several factors causing variation in blood sugar levels, some of them are [5]:

i. Fasting

ii. Stress

iii. Infection

iv. Medications such as steroids

Hemoglobin A1c (HbA1c) Levels

Hemoglobin A1c (HbA1c) level gives a good idea of the blood sugar level over the past three months, thereby helping in the modification of the treatment to obtain the target level [5-6]. Elevated HbA1c links to morbidity, mortality, cardiac injury, and postoperative infection [11]. It might be prudent to postpone the elective procedure when $\mathrm{HbA} 1 \mathrm{c}$ level is found $>9 \%$ or $<5 \%$ to prevent the acute metabolic problems or occurrences of hypoglycemic episodes respectively, perioperatively [5].

Blood Glucose Levels

Blood sugars $>200 \mathrm{mg} / \mathrm{dl}$ are associated with morbidity and mortality in a postoperative period [44-46]. The demonstration of a recent dysregulation in blood glucose during perioperative monitoring is not reflected 
through $\mathrm{HbA1c}[5]$.

Hypoglycemia during the perioperative period can cause a significant challenge. In cases of autonomic dysfunction, it is not easy to pick and a close vigilance is required to manage it timely [45]. There are many factors that can predispose to low blood sugars including fasting state, irregular food intake postoperatively, impairment of renal or liver function, interactions with medications like quinolone, beta-blockers, heparin, trimethoprim-sulfamethoxazole, etc [5].

\section{Perioperative risk assessment of type 2 diabetes}

Perioperatively, the severity of the following complications of diabetes needs to be assessed:

1. Gastroparesis

2. Heart disease

3. Kidney disease

1. Gastroparesis

It is a quite common complication of long-standing diabetes and may be defined as the slow or delayed emptying of the stomach in the absence of mechanical obstruction [5]. It may present with the following symptoms [47]:

i. Anorexia

ii. Abdominal pain

iii. Nausea

iv. Vomiting

v. Early satiety

vi. Abdominal bloating

It can cause a disturbance in postprandial blood sugars [5]. It poses a risk of aspiration of food contents during anesthesia, therefore, it is important to specifically look for and manage this complication and avoid those medications that can further exacerbate this condition [5].

\section{Cardiac Disease}

Proper risk stratification of the cardiac disease including coronary artery disease, heart failure, and cardiac autonomic neuropathy should be undertaken through a detailed history, examination, and review of the recent cardiac investigations. High-risk cases should be further evaluated and consulted by the cardiologist.

3. Kidney Disease

Renal evaluation is required to avoid kidney injury postoperatively. Urine albumin to creatinine ratio (ACR) and the estimation of the glomerular filtration rate (eGFR) should be determined before performing major surgery [5]. Nephrotoxic agents should be avoided in high-risk cases.

\section{Perioperative hyperglycemia}

High blood sugars in a perioperative period in either group of diabetics or non-diabetics are linked to the increase in the morbidity and mortality postoperatively and therefore are considered an independent risk factor [48-49]. They are associated with the delay in wound healing and postoperative infections [48]. The patient's outlook is improved if hyperglycemia in the perioperative period is well managed [48].

Blood Glucose Targets

Blood sugars above $180 \mathrm{mg} / \mathrm{dl}$ are found to be associated with morbidity, especially infections, and mortality [48]. At the same time, there is always a risk of hypoglycemia while attempting control of blood glucose [48]. This risk should be balanced with the cautious approach and the chances of this happening are decreased when blood sugars are targeted to keep in the range from 140-180 mg/dl. However, a wide range between $90-180 \mathrm{mg} / \mathrm{dl}$ of blood sugars is relatively easy to target [48]. 
1. Fasting for a longer period should be avoided [48].

2. An attempt should be made to schedule surgery in the morning [48].

3. Blood glucose should be targeted $<180 \mathrm{mg} / \mathrm{dl}[48]$.

The approach to perioperative management of diabetes is depicted in Figure 1.

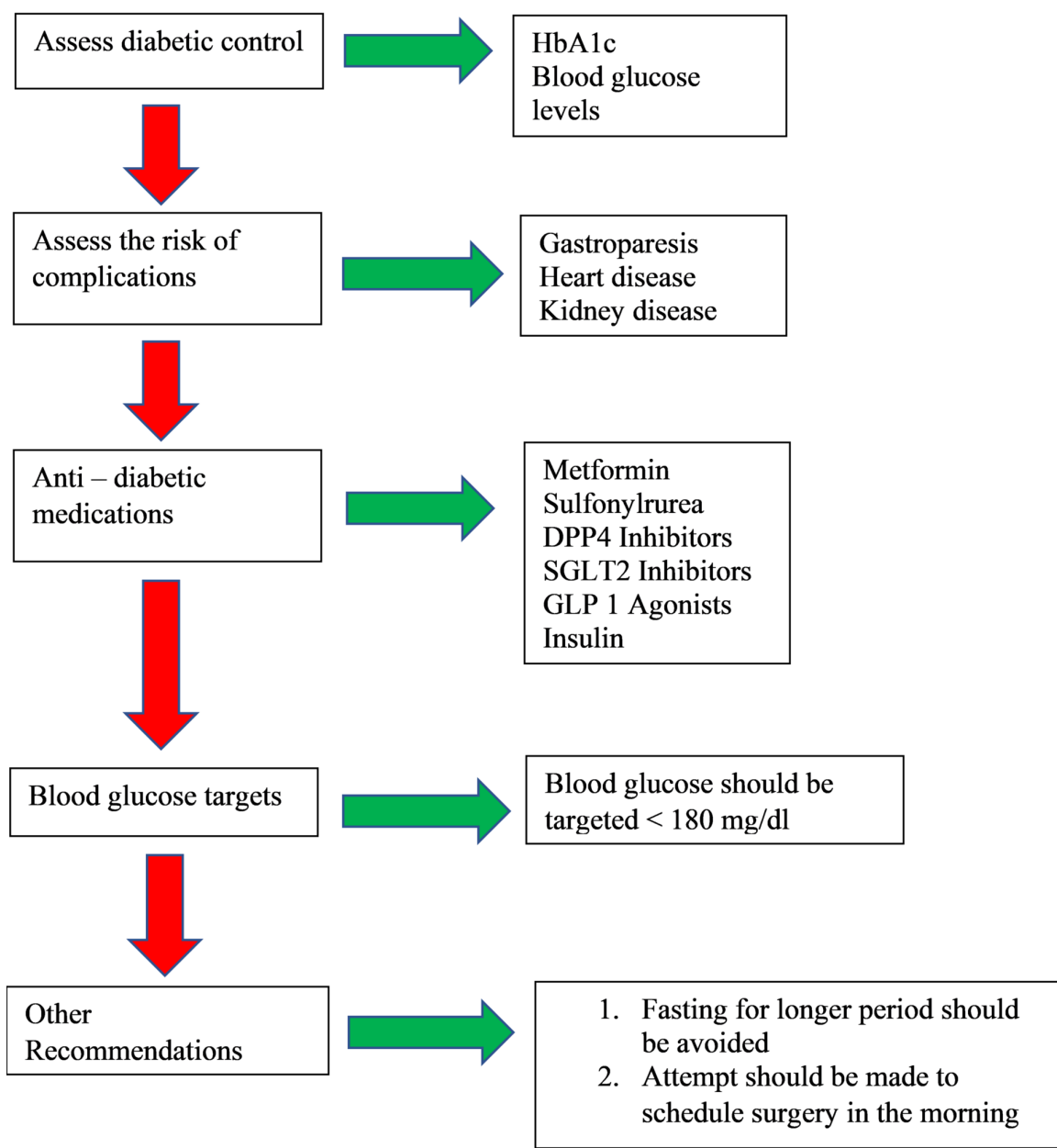

FIGURE 1: Approach to the Perioperative Management of Diabetes

HbA1c: Hemoglobin A1c; DPP4 Inhibitors: Dipeptidyl Peptidase 4 Inhibitors; GLP1 Agonists: Glucagon Like Peptide 1 Agonists; SGLT2 Inhibitors: Sodium - Glucose Transporter 2 inhibitors

\section{Limitations}

In this article, the literature was reviewed pertaining to the perioperative management of blood sugars in patients with adult type 2 diabetes who undergo or being planned for surgery. No quality assessment tool has been applied and the articles over the last five years related to humans were selected. The research papers that were in the English language only were chosen and the studies in other languages were not made part of this article. Another limitation was to select those research articles only who were available as a free text on the database of PubMed. The articles with paid subscriptions were not studied.

Table 4 shows the list of articles that were relevant to the review article. 


\section{Cureus}

\begin{tabular}{|c|c|c|c|c|c|}
\hline SN & $\begin{array}{l}\text { Author's } \\
\text { Name }\end{array}$ & $\begin{array}{l}\text { Year of } \\
\text { Publication }\end{array}$ & $\begin{array}{l}\text { Country } \\
\text { of } \\
\text { Origin } \\
\text { of the } \\
\text { Study }\end{array}$ & Title of the Article & Important Points of the Study \\
\hline 1 & $\begin{array}{l}\text { Deniz } \\
\text { Kuzulugil } \\
\text { et al [1] }\end{array}$ & 2019 & Australia & $\begin{array}{l}\text { Recent advances } \\
\text { in diabetes } \\
\text { treatments and } \\
\text { their perioperative } \\
\text { implications }\end{array}$ & $\begin{array}{l}\text { Preoperative diabetes management is different from center to center. The } \\
\text { convergent approach is required in patients with comorbidities. Sodium glucose } \\
\text { transporter } 2 \text { inhibitors and sulfonylureas should be withheld before major } \\
\text { procedures. }\end{array}$ \\
\hline 2 & $\begin{array}{l}\text { Gaëlle } \\
\text { Cheisson } \\
\text { et al [5] }\end{array}$ & 2018 & France & $\begin{array}{l}\text { Perioperative } \\
\text { management of } \\
\text { adult diabetic } \\
\text { patients: } \\
\text { Preoperative } \\
\text { period }\end{array}$ & $\begin{array}{l}\text { Diabetic control should be evaluated by using haemoglobin A1c and Blood } \\
\text { glucose levels. Assess for gastroparesis, cardiac and renal status. Management } \\
\text { should be individualized depending upon the comorbidities and type of surgery. }\end{array}$ \\
\hline 3 & $\begin{array}{l}\text { Gaëlle } \\
\text { Cheisson } \\
\text { et al [5] }\end{array}$ & 2018 & France & $\begin{array}{l}\text { Perioperative } \\
\text { management of } \\
\text { adult diabetic } \\
\text { patients: } \\
\text { Intraoperative } \\
\text { period }\end{array}$ & $\begin{array}{l}\text { High blood sugars }>180 \mathrm{mg} / \mathrm{dl} \text { peri - operatively carries the risk of morbidity and } \\
\text { mortality. Hypoglycemia may occur when strict blood sugars control is } \\
\text { attempted. }\end{array}$ \\
\hline 4 & $\begin{array}{l}\text { Gaëlle } \\
\text { Cheisson } \\
\text { et al [5] }\end{array}$ & 2018 & France & $\begin{array}{l}\text { Perioperative } \\
\text { management of } \\
\text { adult diabetic } \\
\text { patients: } \\
\text { Postoperative } \\
\text { period }\end{array}$ & $\begin{array}{l}\text { Meticulous monitoring of blood sugars is required to detect and manage hypo } \\
\text { and hyperglycemia. Insulin infusion can be replaced with basal - bolus regime. } \\
\text { Postoperatively, anti - diabetic medications are prescribed by taking into account } \\
\text { previous use of medications, diabetic control, and comorbidities. }\end{array}$ \\
\hline
\end{tabular}

TABLE 4: Relevant articles

\section{Conclusions}

Perioperative management of hyperglycemia is vital to avoid complications and successful outcomes. Blood sugars should be kept from 140 to $180 \mathrm{mg} / \mathrm{dl}$, which is achieved through anti-diabetic medications. The choice of anti-diabetic medications depends on the number of factors including type and duration of surgery, comorbidities of the patients, and estimation of an early resumption of oral intake post surgery. In the usual practice, insulin is used to achieve target blood sugars in a perioperative state affecting the cost and requiring strict monitoring of labs. With the advent of new anti-diabetic medications, does the outlook remain the same or providing other options too? In the daycare settings, or when the patient is expected to be discharged soon, most of the anti-diabetics other than sulfonylureas and SGLT 2 inhibitors, can be continued perioperatively, thus, providing a wide range of choices. The sulfonylureas are associated with a risk of hypoglycemia whereas the SGLT 2 inhibitors are linked to causing diabetic ketoacidosis, especially euglycemic ketoacidosis can be a tricky one to diagnose. The beliefs and fears surrounding metformin are overestimated and it can be used by assessing the overall situation. This emphasizes the individualized approach. The insight into the proper utilization of antihyperglycemic medications other than insulin can boost the confidence and comfort level of both clinicians and patients. However, although there is almost a consensus of keeping blood sugar between 140 and $180 \mathrm{mg} / \mathrm{dl}$ perioperatively, there is no universal guideline for the use of anti-diabetic medications in a perioperative state. In the future, this area might require further exploration to come up with more robust and uniform recommendations.

\section{Additional Information}

\section{Disclosures}

Conflicts of interest: In compliance with the ICMJE uniform disclosure form, all authors declare the following: Payment/services info: All authors have declared that no financial support was received from any organization for the submitted work. Financial relationships: All authors have declared that they have no financial relationships at present or within the previous three years with any organizations that might have an interest in the submitted work. Other relationships: All authors have declared that there are no other relationships or activities that could appear to have influenced the submitted work. 


\section{References}

1. Kuzulugil D, Papeix G, Luu J, Kerridge RK: Recent advances in diabetes treatments and their perioperative implications. Curr Opin Anaesthesiol. 2019 Jun 1, 32:398-404. 10.1097/ACO.0000000000000735

2. Ogurtsova K, da Rocha Fernandes JD, Huang Y, et al.: IDF Diabetes Atlas: global estimates for the prevalence of diabetes for 2015 and 2040. Diabetes Res Clin Pract. 2017, 128:40-50. 10.1016/j.diabres.2017.03.024

3. [[Accessed 13 January 2019]]. Management of adults with diabetes undergoing surgery and elective procedures: improving standards [Internet]. Joint British Diabetes Societies for Inpatient Care. . https://abcd.care/sites/abcd.care/files/resources/Surgical_guidelines_2015_full_FINAL_amended_Mar_2016.pdf..

4. Dhatariya K, Levy N, Kilvert A, et al.: NHS Diabetes guideline for the perioperative management of the adult patient with diabetes. Diabet Med. 2012, 29:420-33. https://doi.org/10.1111/j.1464-5491.2012.03582.x

5. Cheisson G, Jacqueminet S, Cosson E, et al.: Perioperative management of adult diabetic patients. Preoperative period. Anaesth Crit Care Pain Med. 2018, 37:9-19. 10.1016/j.accpm.2018.02.020

6. Sato H, Carvalho G, Sato T, Lattermann R, Matsukawa T, Schricker T: The association of preoperative glycemic control, intraoperative insulin sensitivity, and outcomes after cardiac surgery. J Clin Endocrinol Metab. 2010, 95:4338-44. 10.1210/jc.2010-0135

7. Sathya B, Davis R, Taveira T, Whitlatch $\mathrm{H}, \mathrm{Wu}$ WC: Intensity of peri-operative glycemic control and postoperative outcomes in patients with diabetes: a meta-analysis. Diabetes Res Clin Pract. 2013, 102:8-15. 10.1016/j.diabres.2013.05.003

8. Zhang X, Li T, Li Y, et al.: Protective effect of intraoperative re-dose of prophylactic antibiotics on surgical site infection in diabetic patients: a retrospective cohort study. Ann Transl Med. 2019, 10.21037/atm.2019.01.35

9. Martin ET, Kaye KS, Knott C, et al.: Diabetes and risk of surgical site infection: a systematic review and meta-analysis. Infect Control Hosp Epidemiol. 2016, 37:88-99. 10.1017/ice.2015.249

10. Satake K, Kanemura T, Matsumoto A, Yamaguchi H, Ishikawa Y: Predisposing factors for surgical site infection of spinal instrumentation surgery for diabetes patients. Eur Spine J. 2013, 22:1854-8. 10.1007/s00586-013-2783-8

11. Hemmerling TM, Schmid MC, Schmidt J, Kern S, Jacobi KE. : Comparison of a continuous glucose-insulinpotassium infusion versus intermittent bolus application of insulin on perioperative glucose control and hormone status in insulin-treated type 2 diabetics. J Clin Anesth. 2001, 13:293-300. 10.1016/s09528180(01)00276-8

12. Ljungqvist O, Nygren J, Soop M, Thorell A: Metabolic perioperative management: novel concepts. Curr Opin Crit Care. 2005, 11:295-9. 10.1097/01.ccx.0000166395.65764.71

13. Thomas DJ, Platt HS, Alberti KG: Insulin-dependent diabetes during the peri-operative period An nssessment of continuous glucose-insulin-potaium infusion, and traditional treatment. Anaesthesia. 1984, 39:629-37. 10.1111/j.1365-2044.1984.tb06469.x

14. McCall AL: Insulin therapy and hypoglycemia . Endocrinol Metab Clin North Am. 2012, 1:57-87. 10.1016/j.ecl.2012.03.001

15. Polderman JA, Van Steen SC, Thiel B, et al.: Peri-operative management of patients with type-2 diabetes mellitus undergoing non-cardiac surgery using liraglutide, glucose-insulin-potassium infusion or intravenous insulin bolus regimens: a randomised controlled trial. Anaesthesia. 2018, 73:332-9. 10.1111/anae. 14180

16. American Diabetes Association: Standards of medical care in diabetes-2019 abridged for primary care providers. Clin Diabetes. 2019, 37:11-34. 10.2337/cd18-0105

17. Ljungqvist O, Scott M, Fearon KC: Enhanced recovery after surgery: a review . JAMA Surg. 2017 Mar 1, 152:292-8. 10.1001/jamasurg.2016.4952

18. Barker P, Creasey PE, Dhatariya K, et al.: Peri-operative management of the surgical patient with diabetes 2015: Association of Anaesthetists of Great Britain and Ireland. Anaesthesia. 2015, 70:1427-40. 10.1111/anae.13233

19. Cosson E, Catargi B, Cheisson G, et al.: Practical management of diabetes patients before, during and after surgery: a joint French diabetology and anaesthesiology position statement. Diabetes Metab. 2018, 44:20016. 10.1016/j.diabet.2018.01.014

20. [[Accessed 15 March 2019]]. National Confidential Enquiry into Patient Outcome and Death, 'Highs and Lows,' [Internet]. London, 2018. Available from https://www.ncepod.org.uk/2018pd/Highs\%20and\%20Lows_Summary\%20Report.pdf.The latest installment from the National Confidential Enquiry into Patient Outcome and Death team, with a retrospective case note and questionnaire review, examining the quality of care processes in adult diabetic patients in the perioperative period (being from time of primary care referral to discharge) provides useful insights into the many ways in which we deviate from 'good practice', with recommendations for change. https://www.ncepod.org.uk/2018pd/Highs\%20and\%20Lows_Summary\%20Report.pdf..

21. Lazarus B, Wu A, Shin JI, et al.: Association of metformin use with risk of lactic acidosis across the range of kidney function: a community-based cohort study. JAMA Intern Med. 2018, 1:903-10. 10.1001/jamainternmed.2018.0292

22. Nazer RI, Alburikan KA: Metformin is not associated with lactic acidosis in patients with diabetes undergoing coronary artery bypass graft surgery: a case control study. BMC Pharmacol Toxicol. 2017, 18:38. 10.1186/s40360-017-0145-6

23. Gasanova I, Meng J, Minhajuddin A, Melikman E, Alexander JC, Joshi GP: Preoperative continuation versus interruption of oral hypoglycemics in type 2 diabetic patients undergoing ambulatory surgery: a randomized controlled trial. Anesth Analg. 2018, 127:54-6. 10.1213/ANE.0000000000003675

24. Ishikawa T, Koshizaka M, Maezawa Y, Takemoto M, Tokuyama Y, Saito T, Yokote K: Continuous glucose monitoring reveals hypoglycemia risk in elderly patients with type 2 diabetes mellitus. J Diabetes Investig. 2018, 9:69-74. 10.1111/jdi.12676

25. Azoulay L, Suissa S: Sulfonylureas and the risks of cardiovascular events and death: a methodological metaregression analysis of the observational studies. Diabetes Care. 2017 May 1, 40:706-14. 10.2337/dc16-1943 
26. Zinman B, Wanner C, Lachin JM, et al.: Empagliflozin, cardiovascular outcomes, and mortality in type 2 diabetes. N Engl J Med. 2015, 26:2117-28. 10.1056/NEJMc1600827

27. Wiviott SD, Raz I, Bonaca MP, et al.: Dapagliflozin and cardiovascular outcomes in type 2 diabetes . N Engl J Med. 2019, 24:347-57. 10.1056/NEJMc1902837

28. Neal B, Perkovic V, Mahaffey KW, et al.: Canagliflozin and cardiovascular and renal events in type 2 diabetes. N Engl J Med. 2017, 17 :644-57. 10.1056/NEJMoa1611925

29. Abdul-Ghani MA, Norton L, DeFronzo RA: Role of sodium-glucose cotransporter 2 (SGLT 2) inhibitors in the treatment of type 2 diabetes. Endocr Rev. 2011, 23:515-31. 10.1210/er.2010-0029

30. Liu J, Li L, Li S, Jia P, Deng K, Chen W, Sun X: Effects of SGLT2 inhibitors on UTIs and genital infections in type 2 diabetes mellitus: a systematic review and meta-analysis. Sci Rep. 2017, 6:2824. 10.1038/s41598-01702733-w

31. Blau JE, Tella SH, Taylor SI, Rother KI: Ketoacidosis associated with SGLT2 inhibitor treatment: analysis of FAERS data. Diabetes Metab Res Rev. 2017, 33:2924. 10.1002/dmrr.2924

32. Goldenberg RM, Berard LD, Cheng AY, Gilbert JD, Verma S, Woo VC, Yale JF: SGLT2 inhibitor-associated diabetic ketoacidosis: clinical review and recommendations for prevention and diagnosis. Clin Ther. 2016, 38:2654-64. 10.1016/j.clinthera.2016.11.002

33. Meyer EJ, Gabb G, Jesudason D: SGLT2 inhibitor-associated euglycemic diabetic ketoacidosis: a South Australian clinical case series and Australian spontaneous adverse event notifications. Diabetes Care. 2018 Apr, 1:47-9. 10.2337/dc17-1721

34. Kerridge R, Whyte I, Prior F, Luu J, Story DA: The good, the bad, and the ugly: sodium-glucose cotransporter-2 inhibitors (gliflozins) and perioperative diabetes. 10.1177/0310057X1804600202

35. Peacock SC, Lovshin JA: Sodium-glucose cotransporter-2 inhibitors (SGLT-2i) in the perioperative setting . Can J Anaesth. 2018, 65:143-7. 10.1007/s12630-017-1019-5

36. Garber AJ: Long-acting glucagon-like peptide 1 receptor agonists: a review of their efficacy and tolerability . Diabetes care. 2011, 34:279-84. 10.2337/dc11-s231

37. Polderman JA, Van Steen SC, Thiel B, et al.: Peri-operative management of patients with type-2 diabetes mellitus undergoing non-cardiac surgery using liraglutide, glucose-insulin-potassium infusion or intravenous insulin bolus regimens: a randomised controlled trial. Anaesthesia. 2018, 73:332-9. 10.1111/anae. 14180

38. Abuannadi M, Kosiborod M, Riggs L, House J, Hamburg M, Kennedy K, Marso S: Management of hyperglycemia with the administration of intravenous exenatide to patients in the cardiac intensive care unit. Endocr Pract. 2012 Nov, 27:81-90. 10.4158/EP12196.OR

39. Pfeffer MA, Claggett B, Diaz R, et al.: Lixisenatide in patients with type 2 diabetes and acute coronary syndrome. N Engl J Med. 2015, 3-373. 10.1056/NEJMoa1509225

40. Marso SP, Daniels GH, Brown-Frandsen K, et al.: Liraglutide and cardiovascular outcomes in type 2 diabetes . N Engl J Med. 2016, 28:311-22. 10.1056/NEJMoa1603827

41. Marso SP, Bain SC, Consoli A, et al.: Semaglutide and cardiovascular outcomes in patients with type 2 diabetes. N Engl J Med. 2016, 10:1834-44. 10.1056/NEJMoa1607141

42. Lipš M, Mráz M, Kloučková J, et al.: Effect of continuous exenatide infusion on cardiac function and perioperative glucose control in patients undergoing cardiac surgery: a single-blind, randomized controlled trial. Diabetes Obes Metab. 2017, 19:1818-22. 10.1111/dom.13029

43. Umpierrez GE, Smiley D, Jacobs S, et al.: Randomized study of basal-bolus insulin therapy in the inpatient management of patients with type 2 diabetes undergoing general surgery (RABBIT 2 surgery). Diabetes care. 2011, 34:256-61. 10.2337/dc10-1407

44. Lazar HL, Chipkin SR, Fitzgerald CA, Bao Y, Cabral H, Apstein CS: Tight glycemic control in diabetic coronary artery bypass graft patients improves perioperative outcomes and decreases recurrent ischemic events. Circulation. 2004, 30:1497-502. 10.1161/01.CIR.0000121747.71054.79

45. Bhamidipati CM, LaPar DJ, Stukenborg GJ, Morrison CC, Kern JA, Kron IL, Ailawadi G: Superiority of moderate control of hyperglycemia to tight control in patients undergoing coronary artery bypass grafting. J Thorac Cardiovasc Surg. 2011, 141:543-51. 10.1016/j.jtcvs.2010.10.005

46. Desai SP, Henry LL, Holmes SD, Hunt SL, Martin CT, Hebsur S, Ad N: Strict versus liberal target range for perioperative glucose in patients undergoing coronary artery bypass grafting: a prospective randomized controlled trial. J Thorac Cardiovasc Surg. 2012, 143:318-25. 10.1016/j.jtcvs.2011.10.070

47. Kempler P, Amarenco G, Freeman R, et al.: Management strategies for gastrointestinal, erectile, bladder, and sudomotor dysfunction in patients with diabetes. Diabetes Metab Res Rev. 2011, 27:665-77. 10.1002/dmrr.1223

48. Cheisson G, Jacqueminet S, Cosson E, et al.: Perioperative management of adult diabetic patients. Intraoperative period. Anaesth Crit Care Pain Med. 2018, 37:21-5. 10.1016/j.accpm.2018.02.018

49. Doenst T, Wijeysundera D, Karkouti K, Zechner C, Maganti M, Rao V, Borger MA: Hyperglycemia during cardiopulmonary bypass is an independent risk factor for mortality in patients undergoing cardiac surgery. I Thorac Cardiovasc Surg. 2005, 130:1144-1. 10.1016/j.jtcvs.2005.05.049 